\title{
Action of Melatonin on Severe Acute Liver Failure in Rats
}

\author{
Jeferson de Oliveira Salvi ${ }^{1,4}$, Elizângela Gonçalves Schemitt ${ }^{2}$, Josieli Raskopf \\ Colares $^{2}$, Renata Minuzzo Hartmann ${ }^{2}$, Cláudio Augusto Marroni ${ }^{3}$, Norma Anair \\ Possa Marroni ${ }^{2,4}$ \\ ${ }^{1}$ Departament of Pharmacy, Lutheran University Center of Ji-Paraná, Brazil \\ ${ }^{2}$ Federal University of Rio Grande do Sul, Rio Grande do Sul, Brazil \\ ${ }^{3}$ Federal University of Health Sciences of Porto Alegre, Brazil \\ ${ }^{4}$ Laboratory of Oxidative Stress and Antioxidants, Lutheran University of Brazil, Brazil.
}

\begin{abstract}
Severe acute liver failure (ALF) manifests itself as a rare syndrome, with multiple etiologies for similar clinical conditions. Melatonin (MLT) is a lipophilic indolamine that is synthesized in the pineal gland from serotonin. This study was designed to evaluate hepatic changes resulting from the thioacetamide-induced ALF model, as well as the effects of MLT treatment in male Wistar rats $(n=56)$ in 24- and 48-h experiments. The results indicate a hepatoprotective effect of MLT, with no difference between the studied times, and increased animal survival.
\end{abstract}

Keywords: N-acetyl-5- methoxytryptamine, antioxidant, oxidative stress, liver failure

\section{Introduction}

Hepatopathies are recognized as one of the major health problems worldwide, since they involve different etiological agents and are associated with different outcomes. In this context, severe acute liver failure (ALF) represents a life-threatening condition. The rapid dysfunctional course of a previously normal liver is responsible for a high mortality rate [1].

ALF is the situation that occurs when there is severe acute liver injury, with necrosis of most hepatocytes without clear and rapid regeneration in a previously normal liver, and which causes severe changes in coagulation, with a clinical picture of encephalopathy and coma [2-3]. It manifests itself as a rare, multiple etiology syndrome with similar clinical conditions. Hepatocyte lesions are accompanied by pronounced coagulopathies, but depending on the cause and the complications involved, hypotension, sepsis, immunosuppression, cardiorespiratory dysfunction and liver failure can be observed [4-5].

Recent scientific findings indicate the relationship of oxidative stress with changes in energetic substrates and in the increased activation of enzymes generating reactive oxygen species (ROS) that promote hepatic damage, in addition to the role of pro-inflammatory and vasodilating cytokines in the pathophysiology of the disease [6-8].

The number of research studies with antioxidant molecules has increased in recent years, motivated by the need to understand the mechanisms involved in oxidative stress and restoration of the capacity to combat ROS. Different pathological conditions, including those affecting the liver, have been studied and a considerable number of substances have been shown to be promising, among them melatonin (MLT) [9-11].

MLT, N-acetyl-5-methoxytryptamine, is an indolamine that is synthesized from serotonin, derived from the amino acid tryptophan. The potential antioxidant effect of MLT and its metabolites is well documented by several scientific evidences. The property of interacting with the electron transport complex in the respiratory chain, accepting or donating electrons, and inhibiting lipid peroxidation (LPO) is ascribed to MLT [12].

The hepatoprotective effect of MLT was demonstrated by Pi et al. [13] when they observed increased SIRT3 protein activity and SOD2 acetylation. These findings confirm the probable hepatoprotective role of melatonin in severe fulminant hepatitis, as evidenced by Korkmaz et al. [14] in the fight against ROS and reactive nitrogen species (RNS). The administration of MLT by oral route also positively influenced mitochondrial liver dysfunctions, reducing hepatic steatosis in obese diabetic rats, indicating its likely therapeutic action [15].

Investigating the effects of MLT on ALF thus means searching for an alternative therapy for a condition of high morbidity and mortality, in order to reduce the damage caused by ROS and inhibit or even prevent the progression of the disease. In addition, the present study aimed to evaluate the hepatic alterations resulting from the severe acute liver failure model, as well as the effects of melatonin treatment in two experiments of 24 and 48 hours. 


\subsection{Bioethical Considerations}

\section{Experimental Part}

The study was carried out at the Laboratory of Oxidative Stress and Antioxidants of the Lutheran University of Brazil (ULBRA), in Canoas, Rio Grande do Sul, Brazil, after approval by the Ethics Committee on Animal Use (CEUA - 2016.120, June 23, 2016).

Animal handling complied with the ethical principles of animal experimentation in accordance with the Brazilian legislation in force (Law 11.794/2008) and the standards of the National Council for Control of Animal Experimentation (CONCEA), in accordance with the state animal protection code, respecting as well the local procedures established for the care and use of animals.

\subsection{The animals}

Fifty-six male Wistar rats weighing between 200 and 300 grams were used and maintained in the research animal facility of ULBRA (RS). During the experiment, the animals were kept in boxes $(47 \mathrm{~cm} \times 34 \mathrm{~cm}$ $\mathrm{x} 18 \mathrm{~cm}$ ) covered with wood shavings, in a 12 hours light/dark cycle and temperature between 18 and 22 ${ }^{\circ} \mathrm{C}$. Water and food were given ad libitum.

In order to detect a difference in the magnitude of 1.5 standard deviations (major effect), as assessed by histological parameters, estimating $\alpha=0.05$ and $\beta=90 \%$, at least seven animals per group were necessary.

\subsection{Experimental groups}

The animals were randomized into eight groups $(\mathrm{n}=7)$. Four groups were evaluated at 24 hours: Control 24h (CO-24), Control MLT 24h (CO+MLT-24), Thioacetamide 24h (TAA-24) and Treatment 24h (TAA+MLT-24). The other groups were evaluated at 48 hours: Control 48h (CO-48), Control MLT 48h (CO+MLT-48), Thioacetamide 48h (TAA-48) and Treatment 48h (TAA+MLT-48).

\subsection{Induction of severe acute liver failure and melatonin administration}

Severe acute liver failure was induced by administering two doses of $400 \mathrm{mg} / \mathrm{kg} / \mathrm{animal}$ of thioacetamide (TAA) diluted in saline solution and given intraperitoneally (ip), with an interval of 8 hours from each other for both experiments, following the model proposed by Schemitt et al. [16], as shown in Table 1.

The solution was prepared at the time of administration, under light protection. For this purpose, we used MLT (Chemical ${ }^{\circledR}$ Sigma, St. Louis, M) at a dose of $20 \mathrm{mg} / \mathrm{kg}$ per animal, administered with 500 uL of vehicle composed of sodium chloride $(\mathrm{NaCl} \quad 0.9 \%)$ and $5 \quad \mathrm{uL}$ ethanol $(1 \% \mathrm{EtOH})$, and respecting the circadian cycle of animals.

Table 1. Distribution of animals per group, characterization and description of the number of doses administered.

\begin{tabular}{|c|c|}
\hline Group & Administered intraperitoneally (ip) \\
\hline 24-hour control (CO-24) & 3 doses of $1 \mathrm{ml}$ of vehicle $(0.9 \% \mathrm{NaCl}$ and $1 \% \mathrm{EtOH})$ \\
\hline Control MLT 24h (CO+MLT-24) & 2 doses of $1 \mathrm{ml}$ of vehicle $(0.9 \% \mathrm{NaCl}$ and $1 \% \mathrm{EtOH})$ and 1 dose of MLT $(20 \mathrm{mg} / \mathrm{kg} / \mathrm{animal})$ \\
\hline Thioacetamide 24h (TAA-24) & 2 doses of thioacetamide $(400 \mathrm{mg} / \mathrm{kg})$ and 1 dose of $1 \mathrm{ml}$ of vehicle $(0.9 \% \mathrm{NaCl}$ and $1 \% \mathrm{EtOH})$ \\
\hline $\begin{array}{l}\text { 24-hour treatment (TAA+MLT- } \\
\text { 24) }\end{array}$ & 2 doses of thioacetamide $(400 \mathrm{mg} / \mathrm{kg})$ and 1 dose of MLT $(20 \mathrm{mg} / \mathrm{kg} / \mathrm{animal})$ \\
\hline 48h Control (CO-48) & 5 doses of $1 \mathrm{ml}$ of vehicle $(0.9 \% \mathrm{NaCl}$ and $1 \% \mathrm{EtOH})$ \\
\hline Control MLT 48h (CO+MLT-48) & 2 doses of $1 \mathrm{ml}$ of vehicle $(0.9 \% \mathrm{NaCl}$ and $1 \% \mathrm{EtOH})$ and 3 doses of MLT $(20 \mathrm{mg} / \mathrm{kg} / \mathrm{animal})$ \\
\hline Thioacetamide 48h (TAA-48) & 2 doses of thioacetamide $(400 \mathrm{mg} / \mathrm{kg})$ and 3 doses of $1 \mathrm{~mL}$ vehicle $(0.9 \% \mathrm{NaCl}$ and $1 \% \mathrm{EtOH})$ \\
\hline Treatment 48 h (TAA + MLT-48) & 2 doses of thioacetamide $(400 \mathrm{mg} / \mathrm{kg})$ and 3 doses of MLT $(20 \mathrm{mg} / \mathrm{kg} / \mathrm{animal})$ \\
\hline
\end{tabular}

\subsection{Survival of animals}

Animal survival for the 24- and 48-hour experiments after administration of the first dose of TAA was assessed through the Kaplan-Meier curve analysis. The method divides the follow-up period into intervals, assigning limits that correspond to the time at which the events occur, which allows the best evaluation of these [17].

\subsection{Tissue and blood sampling and death of animals}

After 24 and 48 hours post TAA administration, the animals were weighed and anesthetized with a solution of ketamine hydrochloride $(95 \mathrm{mg} / \mathrm{kg})$ and $2 \%(8 \mathrm{mg} / \mathrm{kg})$ xylazine hydrochloride (ip). Subsequently, blood was collected by puncture of the retro-orbital plexus with a capillary glass tube and placed in a test tube with heparin to prevent coagulation.

The animals were submitted to euthanasia by excess anesthetics, i.e. at a dose three times higher than usual, following the euthanasia practice guidelines of the National Animal Experimentation Control Council [18]. 
After confirmation of deaths, the abdominal region was shaved and disinfected for subsequent surgical intervention, starting with medial ventral laparotomy and then removing the liver for analysis and storage in sections. One fragment was immersed in $10 \%$ formaldehyde solution for 24 hours for histological analysis and another fragment was frozen $\left(-80^{\circ} \mathrm{C}\right)$ for posterior LPO analysis and antioxidant enzyme evaluation.

\subsection{Biochemical analyses}

The concentration of protein in liver homogenate was determined according to Bradford [19]. LPO was investigated through the ability to react with thiobarbituric acid (TBARS) and the results were expressed in nmoles/mg protein [20]. We evaluated the activities of antioxidant enzymes superoxide dismutase (SOD) [21], catalase (CAT) [22], glutathione peroxidase (GPx) [23] and glutathione S-transferase (GST) [24]. The production of nitric oxide metabolites $\left(\mathrm{NO}_{2} / \mathrm{NO}_{3}\right)$ was measured indirectly by the Griess reaction [25].

\subsection{Histological analysis of hepatic tissue}

For microscopic analysis, slices of liver fragments were stained with hematoxylin-eosin (HE). First, the tissue samples were fixed in $10 \%$ formalin and embedded in paraffin. In the next step the paraffin blocks were cut into 3 -micron $(3 \mu)$ sections using a microtome (Leitz $\left.{ }^{\circledR} 1512\right)$. In the staining step, the slides were immersed in hematoxylin-eosin for five minutes each, then subjected to a tap water bath. In the dehydration phase, the structures passed through three containers with absolute alcohol and two with xylol. After this procedure, a coverslip was placed on the slide using Canada's Balsam or Entellan, thus completing the preparation process.

The slides were evaluated by blinded researcher, without previous knowledge of the groups, using a microscope equipped with a digital camera to capture images by means of Image-Plus software (Media Cybernetics®, Bethesda, USA).

\subsection{Immunohistochemistry}

Tissue samples were fixed in $10 \%$ formalin and embedded in paraffin, to be subsequently deparaffinized using xylol and proceed to rehydration in different ethanol degrees. The antigen recovery was performed in microwaves in citrate buffer at $100{ }^{\circ} \mathrm{C}$ and the endogenous peroxidase activity was blocked by incubating the slides in absolute methanol containing $3 \%$ hydrogen peroxide at room temperature.

The sections were preincubated sequentially with $10 \%$ rabbit serum at room temperature, in order to block possible undesired secondary antibody reactions. Slides were incubated with polyclonal iNOS antibodies (SC-7271), NF-кB (subunit p65) (SC-372) and TNF- $\alpha$ (SC-8301) (Santa Cruz Biotechnology ${ }^{\circledR}$, Santa Cruz, CA, USA), dilution 1:200 overnight at $4{ }^{\circ} \mathrm{C}$. After this period, the slides were washed with buffer and incubated with biotinylated anti-rabbit $\mathrm{IgG}$ secondary antibody for 30 minutes at room temperature. Then the slides were treated with EnVision ${ }^{\circledR}$ reagent and subjected to three washes with phosphate-buffered saline (PBS). The nuclei were stained with hematoxylin, the primary antibody was diluted in PBS, containing bovine albumin as a negative control.

The results were evaluated by a pathologist, who had no prior knowledge of the groups, through a microscope equipped with a digital camera to capture images by means of software Image-Plus (Media Cybernetics ${ }^{\circledR}$, Bethesda, USA).

\subsection{Statistical analysis of data}

The quantitative data generated were described by mean and standard deviation. The comparison between groups was performed by analyzing variables of repeated measures by one-way ANOVA. The location of the difference was performed by the Student Newman-Keuls procedure and the data analyzed with software GraphPad INSTAT 3.1. Values were considered significant at $\mathrm{p}<0.05$.

\section{Results and Discussion}

Severe ALF is a syndrome that occurs in the healthy liver or liver already with chronic disease, which may rapidly evolve to the fulminant form. The experimental models for understanding pathophysiological aspects and the definition of therapeutic intervention strategies for treating ALF have become diversified and increased in recent years [26].

The TAA model induces ALF in its fulminant form with centrilobular necrosis, enzymatic alterations, decreased coagulation and nitric oxide, ascribed to the ability of covalent modification in cellular nucleophiles, lipids and proteins. This experimental model mimics the physiopathogenic and pathophysiological aspects of the disease in humans and helps in the understanding of its progress and the possibility of therapeutic intervention [16, 27-29]. 


\subsection{Survival of animals}

Animal survival was evaluated by means of the Kaplan-Meier curve (Fig. 1). The occurrence of deaths was recorded from the thirty-ninth hour following ALF induction, only for the TAA group. For these animals, a significant difference $(\mathrm{p}<0.001)$ between the survival curves was also observed as compared to the MLT group.

At the end of the 48-hour experiment, the TAA group presented survival of approximately $30 \%$, in contrast to the TAA+MLT group, where survival was $100 \%$. Similar results were previously reported in the literature using MLT in the treatment of different induced pathological conditions in animal models, such as sepsis [30-31], Alzheimer [32], and liver injury caused by cholangiocarcinoma [33].

\subsection{Analysis of hepatic integrity}

Table 2 shows the result for enzyme concentrations associated with liver damage in the 24-hour experiment. For the TAA group, a significant increase was observed for all the enzymes evaluated as compared to the $\mathrm{CO}$ and CO+MLT groups. Exposure to melatonin, however, was able to significantly reduce these levels $(\mathrm{p}<0.001)$.

The highest enzymatic activity recorded was associated with elevated AST in the TAA group. This increase was higher as compared to the $\mathrm{CO}$ group and the greatest reduction of this value was obtained in the group receiving MLT. For the ALT enzyme, the same representative increase was observed as compared to the $\mathrm{CO}$ and $\mathrm{CO}+\mathrm{MLT}$ groups. In relation to the $\mathrm{CO}$ and $\mathrm{CO}+\mathrm{MLT}$ groups, FA enzyme activity increased significantly and was significantly reduced as well.

The results of enzymatic activity for the 48 hour experiment show that serum levels of all enzymes were also significantly higher $(\mathrm{p}<0.001)$ in the TAA group than in the CO and CO+MLT groups. For the TAA+MLT group, just like in the 24-hour experiment, a decrease $(\mathrm{p}<0.05)$ in enzyme activity was observed.

The significant increase in AST and ALT $(\mathrm{p}<0.001)$ is related to the presence of increased liver damage, either by increased cell membrane permeability and intracellular extravasation or by hepatocyte necrosis [34].

$\mathrm{AF}$ is expressed in the hepatocyte canalicular membrane and its elevation means cholestasis, which may be related to drug use or xenobiotics [35-36].

The antioxidant, anti-inflammatory and hepatoprotective activity observed in the present study is corroborated by recent research relating lower activity of aminotransferases and AF to the influence of MLT as a therapeutic intervention [37].

Decreased levels of AST, ALT and AF have been reported in a model of TAA-induced liver fibrosis in MLT-treated rats and in the pretreatment of cyclophosphamide-induced hepatotoxicity [38]. Similar result was found for the same ALT induction model, used in the present study, using quercetin and glutamine, both as monotherapy [16, 39-40].

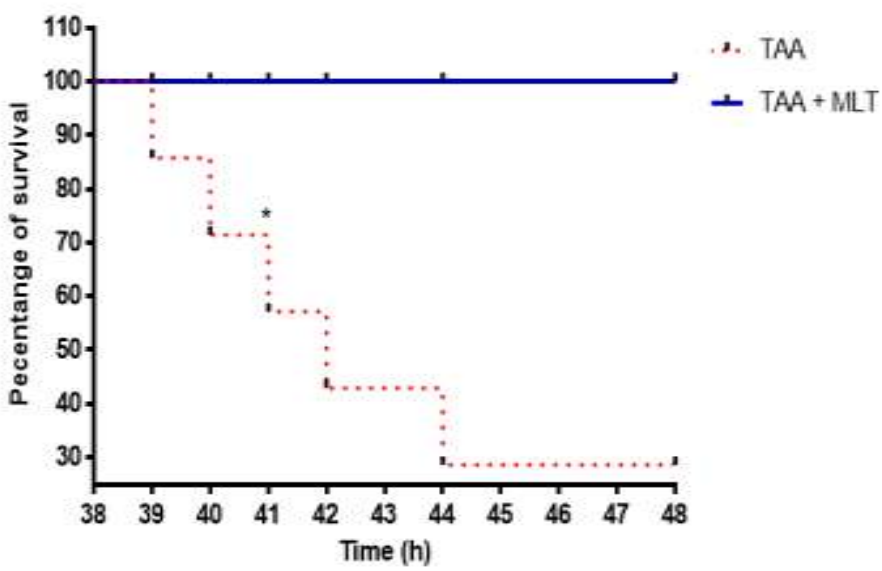

Figure 1. Kaplan-Meier curve for the frequency of animal survival for TAA and TAA+MLT groups, in the 48hour experiment. *Significant difference between curves ( $\mathrm{p}=0.0007$ ), Long Rank (Mantel-Cox) test. 
Table 2. Serum concentrations of hepatic enzymes aspartate aminotransferase (AST), alanine aminotransferase (ALT) and alkaline phosphatase (ALP) for the 24- and 48-hour experiments.

\begin{tabular}{|l|l|l|l|l|}
\hline Enzymes & CO & CO + MLT & TAA & TAA + MLT \\
\hline 24h & & & & \\
\hline AST (U/L) & $36.12( \pm 7.38)$ & $41.66( \pm 5.12)$ & $415.98( \pm 32.18)^{*}$ & $258.56( \pm 22.64)^{\#}$ \\
\hline ALT U/L) & $21.85( \pm 2.04)$ & $24.64( \pm 3.46)$ & $265.48( \pm 8.49)^{*}$ & $62.48( \pm 5.15)^{\#}$ \\
\hline FA (U/L) & $15.03( \pm 0.95)$ & $16.99( \pm 1.81)$ & $56.62( \pm 2.03)^{*}$ & $23.59( \pm 1.83)^{\#}$ \\
\hline $\mathbf{4 8 h}$ & & & & \\
\hline AST (U/L) & $35.42( \pm 6.98)$ & $39.46( \pm 4.66)$ & $564.92( \pm 78.45)^{*}$ & $284.23( \pm 53.48)^{\#}$ \\
\hline ALT U/L) & $24.57( \pm 3.954)$ & $29.48( \pm 3.62)$ & $294.36( \pm 15.39)^{*}$ & $62.34( \pm 9.45)^{\#}$ \\
\hline FA (U/L) & $16.45( \pm 1.55)$ & $18.64( \pm 1.36)$ & $65.34( \pm 3.46)^{*}$ & $25.64( \pm 1.79)^{\#}$ \\
\hline
\end{tabular}

Data are expressed as mean ( \pm standard deviation). *Significant increase in relation to CO and CO+MLT groups $(\mathrm{p}<0.001)$. ${ }^{\#}$ Significant reduction relative to the TAA group $(\mathrm{p}<0.001$ and $\mathrm{p}<0.05)$.

\subsection{Total protein levels}

As shown in Fig. 2, analysis of total protein concentrations indicated a significant reduction $(\mathrm{p}<0.001)$ between the TAA and the CO and CO+MLT groups, for both periods of 24 and 48 hours. A comparison of TAA values with those of the TAA+MLT groups shows a significant increase $(\mathrm{p}<0.01)$ after 24 and 48 hours.

For both experiments, 24 and 48 hours, the total protein level was higher in the MLT-treated groups than in the TAA group. This finding suggests the role of MLT in protecting hepatocytes with consequent maintenance or resistance of protein integrity. Recent studies indicate that the hepatoprotection granted by MLT, administered alone as monotherapy or with other antioxidant substances, may be effective against the effects of TAA and other toxic agents [41-42].

\subsection{Lipoperoxidation}

The results for LPO are shown in Fig. 3. For the two periods evaluated, the TAA groups showed a marked increase $(\mathrm{p}<0.001)$ as compared to the $\mathrm{CO}$ and CO+MLT groups. These values were significantly reduced $(\mathrm{p}<0.01)$ as compared to melatonin-treated animals (TAA+MLT). LPO can trigger the synthesis and proliferation of hepatic stellate cells due to oxidative stress. Furthermore, the Kupffer cells are more likely to be stimulated and produce cytokines, such as TNF- $\alpha$, increasing inflammation and inducing apoptosis. In addition, LPO reduces activity of the mitochondrial respiratory chain producing more ROS and increasing oxidative stress [43]. LPO levels, detected by the TBARS technique, were higher in the TAA group and reduced in both MLT-treated groups, suggesting its protective effect. In amitriptyline-induced hepatotoxicity, in cirrhosis by carbon tetrachloride use and by bile duct ligation, MLT-treated animals also achieved significantly lower LPO $[41,44-46]$. Similar results were obtained with quercetin and glutamine in the treatment of TAA-induced ALF $[16,39]$.

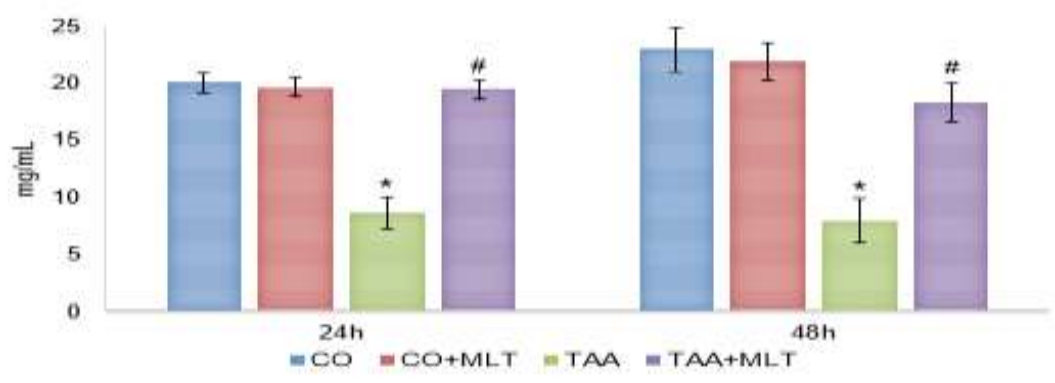

Figure 2. Total protein concentrations determined by the Bradford method for the different experimental groups after 24 and 48 hours (control group $=\mathrm{CO}, \mathrm{CO}+\mathrm{MLT}=$ melatonin group, TAA $=$ thioacetamide group, TAA+MLT = melatonin-treated group). Data are expressed as mean \pm standard deviation. *Significant decrease in relation to $\mathrm{CO}$ and CO+MLT groups $(\mathrm{p}<0.0001)$. "Significant increase compared to the AAR group $(\mathrm{p}<0.01)$.

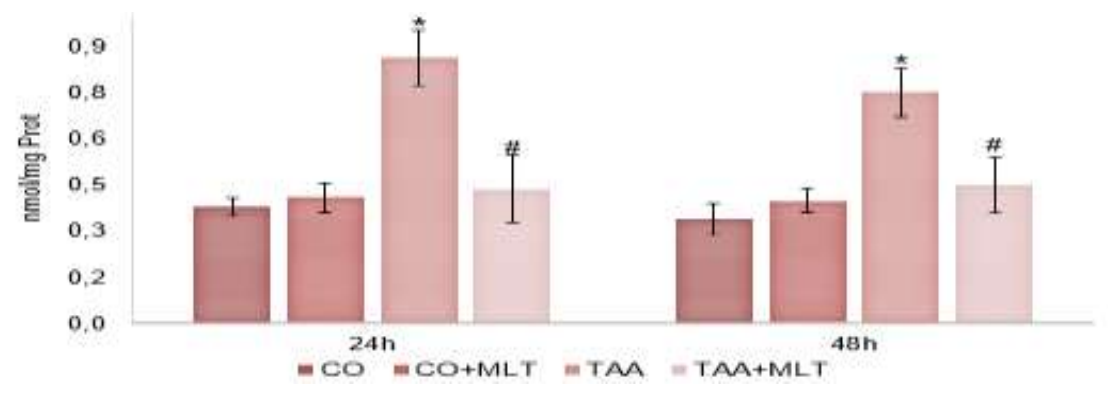


Figure 3. Lipoperoxidation values determined by the technique of thiobarbituric acid reactive substances (TBARS) (nmol/mg protein) in the different experimental groups $(\mathrm{CO}=\mathrm{control}$, MLT=melatonin, TAA=thioacetamide, TAA+MLT=melatonin-treated group). Data are expressed as mean \pm standard deviation. *Significant increase in relation to $\mathrm{CO}$ and CO+MLT groups $(\mathrm{p}<0.001)$. "Significant reduction relative to the TAA group $(\mathrm{p}<0.01)$.

\subsection{Evaluation of Antioxidant Enzymes}

Oxidative damage occurs when the antioxidant defense system, represented endogenously by the antioxidant enzymes, is diminished by the presence of free radicals. The ALF model of the present study used TAA and measured the enzymatic levels of SOD, CAT, GPX and GST.

\subsubsection{Superoxide Dismutase}

SOD activity was greater $(\mathrm{p}<0.01)$ in the TAA than in the CO and CO+MLT groups for the two evaluated periods, but was more expressive after 48 hours $(\mathrm{p}<0.001)$. A significant reduction $(\mathrm{p}<0.01)$ around $50 \%$ in SOD activity was observed in the TAA+MLT groups after 24 and 48 hours (Fig. 4).

SOD is an enzyme that has isoforms, located intracellularly in mitochondria and cytoplasm, responsible for the detoxification of ROS from endogenous and exogenous sources, playing an important role against oxidative stress [47]. LPO due to administration of TAA influences the increase of superoxide anion levels and the higher activity of SOD detected in the TAA groups.

Findings from the present study revealed a reduction in SOD levels for the MLT-treated group within the first 24 hours. Demirtas et al. [48], using the same MLT dosage in the treatment of fructose-induced hepatic cytotoxicity, recorded the same decrease.

\subsubsection{Catalase}

The values found for CAT enzyme activity were significantly lower in the TAA group than in the CO and CO+MLT groups $(\mathrm{p}<0.05)$. The animals receiving the melatonin treatment (TAA+MLT) obtained a significant increase in the $24 \mathrm{~h}(\mathrm{p}<0.05)$ and $48 \mathrm{~h}(\mathrm{p}<0.01)$ experiments (Fig. 5).

Along with SOD, CAT is the first line of defense. The reduction of CAT concentration may be indicative of redox imbalance and consequent cellular oxidative damage, since increased levels of superoxide radicals inhibit its activity [49-50].

In the present study, MLT-treated groups obtained a significant increase in CAT enzyme activity for both research designs ( 24 and 48 hours). Similarly, MLT promoted increased CAT concentration in the models of salivary gland injury and aggression to testicular tissue by ionizing radiation in multiple sclerosis [50-52].

\subsubsection{Glutathione Peroxidase}

Fig. 6 illustrates the values obtained for GPx enzymatic activity. There was an increase in its mean activity after $24(143 \%)$ and $48(171 \%)$ hours for the TAA groups relative to the CO and CO+MLT groups $(\mathrm{p}<0.001)$. When comparing TAA with the TAA+MLT groups, a significant reduction was observed in both evaluated periods $(\mathrm{p}<0.001)$

The redox balance in tissues depends on the proper functioning of glutathione's antioxidant system. The GPX enzyme oxidizes the reduced form of glutathione (GSH) to neutralize LPO. At the same time, GSH is used as substrate by the GST enzyme in the detoxification of compounds that are harmful to the tissue [53].

\subsubsection{Glutathione S-Transferase}

Fig. 7 shows the GST enzyme activity. A comparison of mean values between the TAA, CO and CO+MLT groups showed a significant increase in GST activity in both the 24- and 48-hour experiments $(\mathrm{p}<0.001)$. These values as compared to those of melatonin-treated animals (TAA+MLT) were significantly reduced $(\mathrm{p}<0.001)$.

In the present study, increased GST levels were recorded in the TAA groups for both the 24 and 48hour experiments, evidencing their importance in the detoxification process. MLT administration in the groups with induced ALF promoted a significant reduction in these enzymatic levels. These results are corroborated by previous research confirming MLT's ability to decrease the activity of antioxidant enzymes SOD, GPX and GST at different doses, therapeutic regimens and hepatoxicity models, supporting the benefits of MLT in the modulation of oxidative stress $[42,54-56]$. 


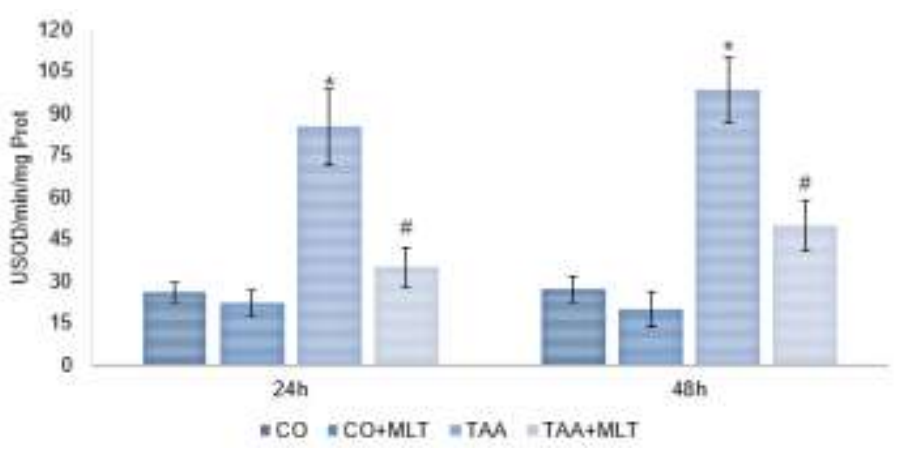

Figure 4. SOD activity (USOD/min/mg protein) in the experimental groups $(\mathrm{CO}=$ control group, $\mathrm{CO}+\mathrm{MLT}=$ melatonin group, TAA=thioacetamide group, TAA+MLT=melatonin-treated group) after 24 and 48 hours. Data are expressed as mean \pm standard deviation. *Significant increase in relation to CO group and CO+MLT group $(\mathrm{p}<0.01)$. ${ }^{\#}$ Significant reduction relative to the TAA. group $(\mathrm{p}<0.01)$.

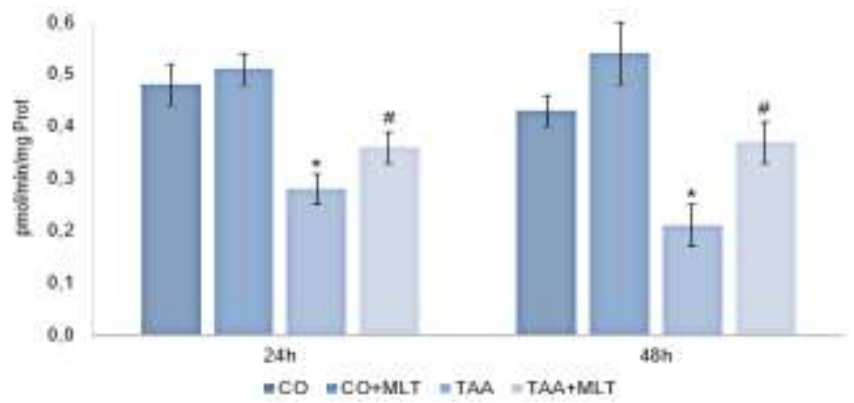

Figure 5. CAT enzyme activity (pmol/min/mg protein) after 24 and 48 hours in the different experimental groups $(\mathrm{CO}=\mathrm{Control}$ group, $\mathrm{CO}+\mathrm{MLT}=$ melatonin group, $\mathrm{TAA}=$ thioacetamide group, $\mathrm{TAA}+\mathrm{MLT}=$ melatonintreated group). Data are expressed as mean \pm standard deviation. *Significant decrease in relation to CO group and CO+MLT group ( $\mathrm{p}<0.05)$. "Significant increase compared to the AAR group $(\mathrm{p}<0.05)$.

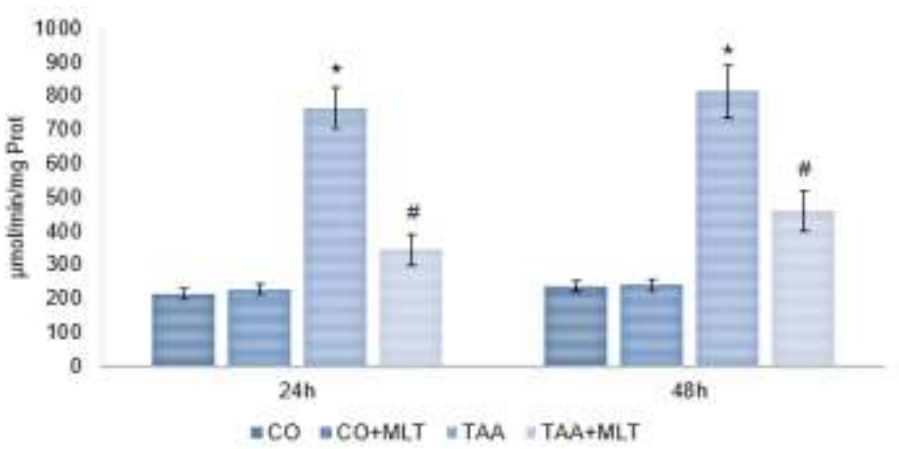

Figure 6. GPx activity (pmol/min/mg protein) after 24 and 48 hours in the different experimental groups $(\mathrm{CO}=$ Control group, $\mathrm{CO} \mathrm{MLT}=$ melatonin group, $\mathrm{TAA}=$ thioacetamide group, $\mathrm{TAA}+\mathrm{MLT}=$ melatonin-treated group). Data are expressed as mean \pm standard deviation. *Significant increase in relation to CO groups and CO+MLT group $(\mathrm{p}<0.001)$. ${ }^{\#}$ Significant reduction relative to the TAA group $(\mathrm{p}<0.001)$.

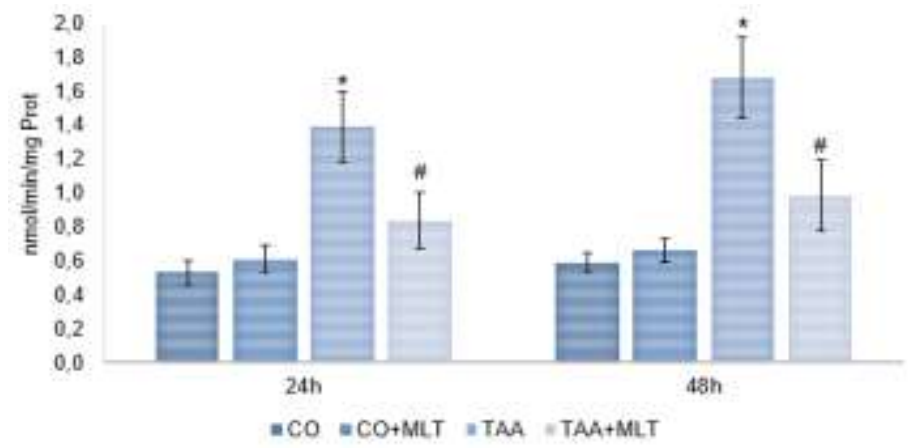


Figure 7. GST enzyme activity (pmol/min/mg protein) after 24 and 48 hours in the different experimental groups $(\mathrm{CO}=\mathrm{Control}$ group, $\mathrm{CO}+\mathrm{MLT}=$ melatonin group, $\mathrm{TAA}=$ thioacetamide group, $\mathrm{TAA}+\mathrm{MLT}=$ melatonintreated group). Data are expressed as mean \pm standard deviation. *Significant increase in relation to $\mathrm{CO}$ and CO+MLT groups $(\mathrm{p}<0.001)$. \#Significant reduction relative to the TAA group $(\mathrm{p}<0.001)$.

\subsection{Nitric Oxide Metabolites}

Fig. 8 shows $\mathrm{NO}_{2} / \mathrm{NO}_{3}$ levels in both experiments ( 24 and 48 hours). The activity was significantly higher $(\mathrm{p}<0.001)$ in the TAA group as compared to the value obtained between the means of the $\mathrm{CO}$ and CO+MLT groups. For the MLT-treated group (TAA+MLT), there was a significant reduction $(p<0.001)$ in the nitric oxide metabolite levels as compared to the TAA group.

The concentration of nitric oxide metabolites was higher in the TAA group than in the CO and CO+MLT groups, and MLT intervention brought about a decrease in the TAA+MLT group in relation to the TAA group.

The result for the $48 \mathrm{~h}$ experiment also showed a significant superiority $(\mathrm{p}<0.001)$ for metabolites concentration produced in the TAA group, in relation to the average obtained from the $\mathrm{CO}$ and CO+MLT groups, and these levels were reduced $(\mathrm{p}<0.01)$ in the TAA+MLT group.

This study identified increased levels of $\mathrm{NO}_{2} / \mathrm{NO}_{3}$ in the TAA groups, as well as a significant reduction in these values upon administration of MLT. This result is corroborated by previous findings that showed the effectiveness of MLT in reducing the levels of nitric oxide derivatives [57-58].

\subsection{Histopathological analysis}

Hepatic histology in the CO and CO+MLT groups at 24 and $48 \mathrm{~h}$ is normal (A and B). In the TAA group, both at 24 and 48h, we observed tissue disorganization with necrosis ( Ne), inflammatory infiltrate (In), and presence of leukocytes and hemorrhagic zones (He). These changes were more pronounced at $48 \mathrm{~h}$. The TAA+MLT groups (24 and $48 \mathrm{~h}$ ) displayed maintenance of the parenchymal architecture, preservation of hepatocyte integrity with few changes.

In acute hepatitis, the common histological features involve focal necropsies of hepatocytes with cell destruction, portal regions with inflammation and presence of mononuclear cell infiltration, tumescence of Kupffer cell and bile ducts, and cholestasis [36].

The histological analysis for both TAA groups demonstrated disruption and loss of the hepatic tissue organization, and such evidence may be associated with the higher LPO that promotes instability in hepatocyte membranes with consequent rupture and extravasation of intracellular fluid. In the MLT-treated groups, TAA+MLT-24 and TAA+MLT-48h, there is less tissue damage, and such evidence, along with the observed low LPO levels, suggests the hepatoprotective effect of MLT in maintaining the integrity of hepatocyte cell membranes and hepatic integrity enzymes.

A histopathological analysis by Shokrzadeh et al. [38] noted the efficacy of MLT in protecting liver cells, as reported by Serikov and Lyashev [59], who reported a higher concentration of normal hepatocytes and lower liver degeneration due to the use of MLT. In a liver reperfusion model, necroses were not found in MLTtreated tissues [60].

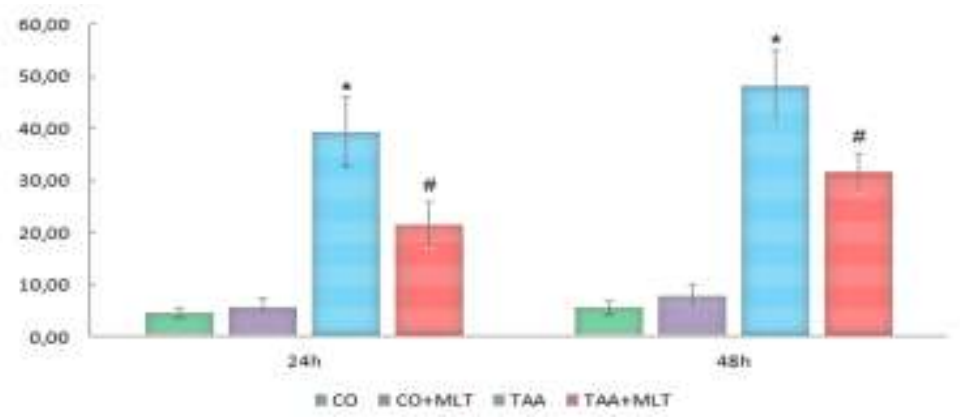

Figure 8. Nitric oxide metabolites activity ( $\mathrm{mmol} / \mathrm{L})$ after 24 and 48 hours in the different experimental groups $(\mathrm{CO}=$ control group, $\mathrm{CO}+\mathrm{MLT}=$ melatonin group, TAA=thioacetamide group, TAA+MLT=melatonin-treated group). Data are expressed as mean \pm standard deviation. *Significant increase in relation to CO and CO+MLT groups ( $\mathrm{p}<0.001)$. "Significant reduction relative to the TAA group $(\mathrm{p}<0.001)$.

\subsection{Immunohistochemical evaluations}

The present study showed a greater expression of all the inflammatory markers investigated in the TAA-24 and TAA-48 groups, as well as a significant decrease in these values in relation to the MLT-treated animals in both experiments. 


\subsubsection{Immunohistochemistry of iNOS}

Figure 10 shows iNOS enzyme expression in the 24 hour experiment. An analysis of the positive pixels (E) showed a significant increase $(\mathrm{p}<0.001)$ in the TAA as compared to the CO (A) and CO+MLT (B) groups. Likewise, a significant reduction $(\mathrm{p}<0.001)$ was observed in the TAA+MLT group (D).

In the $48 \mathrm{~h}$ experiment (Fig. 11), a greater expression of positive pixels (E) was also observed in the TAA (C) as compared to the CO (A) and CO+MLT (B) groups, $\mathrm{p}<0.001$. However, a statistically significant reduction $(\mathrm{p}<0.001)$ was observed when the TAA+MLT group was compared to TAA group (D).

The increase of iNOS in the TAA-24 and TAA-48 groups is related to the higher concentration of NO derivatives. As reported here, MLT's ability to reduce iNOS expression was also demonstrated in previous studies on induced oxidative stress in liver $[42,61]$.

\subsubsection{Immunohistochemistry of NF-кB}

The analysis of the positive pixel expression for NF- $\kappa \mathrm{B}$ in the $24 \mathrm{~h}$ experiment (Fig. 12) showed a significant increase $(\mathrm{p}<0.001)$ as compared to the values of the TAA $(\mathrm{C})$ and CO (A) and CO+MLT (B) groups. Such positive expression was significantly lower in the TAA $(\mathrm{p}<0.001)$ than in the TAA+ MLT group (D).

In the $48 \mathrm{~h}$ experiment (Fig. 13), a highly significant difference $(\mathrm{p}<0.001)$ was observed when pixel expression in the TAA group (C) was compared with the CO (A) and CO+MLT (B) groups. This value is halved compared to the results of the TAA+MLT group (D), also representing a significant decrease $(\mathrm{p}<0.001)$.

\subsubsection{Immunohistochemistry of TNF- $\alpha$}

Fig. 14 shows the images obtained from immunohistochemistry for the $24 \mathrm{~h}$ experiment. Positive pixel expression was higher in the TAA (C), and as compared to the CO (A) and CO+MLT (B) groups this value was significantly increased $(\mathrm{p}<0.001)$. The same analysis demonstrates a significant reduction $(\mathrm{p}<0.001)$ in the MLT+TAA as compared to the TAA group (D).

In the $48 \mathrm{~h}$ experiment (Fig. 15), the same increased pixels expression in the TAA group (C) was observed as compared to the $\mathrm{CO}(\mathrm{A})$ and CO+MLT groups (B). And as the TAA+MLT (D) is compared to the TAA group, the reduction is significant $(\mathrm{p}<0.001)$.

After liver tissue injury, Kupffer cells release certain substances, among which TNF- $\alpha$, which determines the change from mitotic phase $\mathrm{G} 0$ to $\mathrm{G} 1$ in order to promote liver regeneration and at the same time stimulating nuclear transcription factor NF- $\kappa \mathrm{B}$ [62]. Immunohistochemical markers TNF- $\alpha$ and NF- $\kappa \mathrm{B}$ were also significantly decreased in the groups that received treatment with MLT in the hepatic ischemia model [40, $46,63]$. The effect of MLT in the protection of cell membranes, proteins and mitochondrial DNA can be considered an indirect action against oxidative stress in the different injuries that affect the liver. Modulation of the immune system and production of endogenous substances associated with antioxidant, anti-inflammatory and anti-apoptotic functions are also assigned to it [64]. In a viral model of ALF induced in rabbits, MLT showed antioxidant and antiapoptotic effect, in addition to the inhibition of viral RNA replication [65].
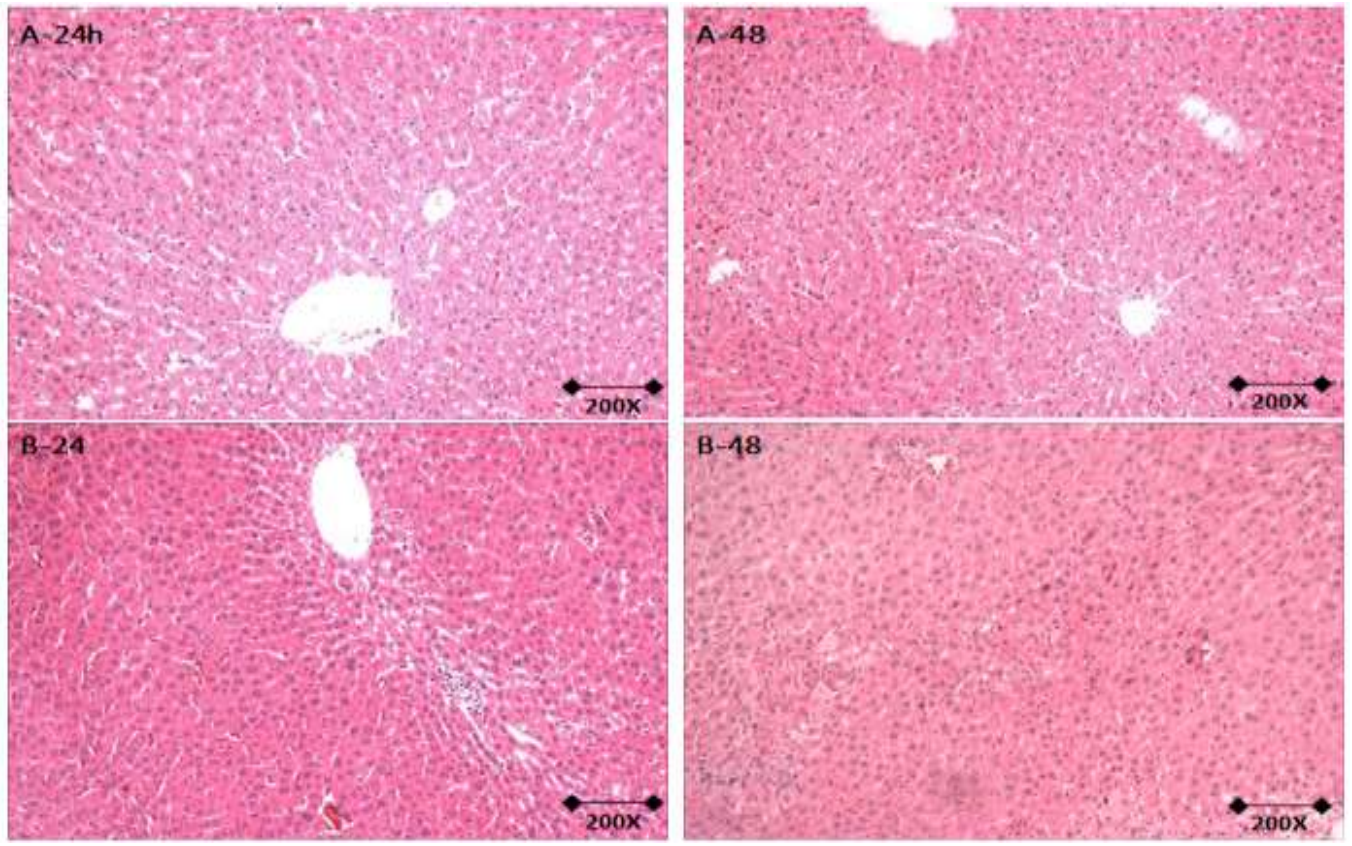

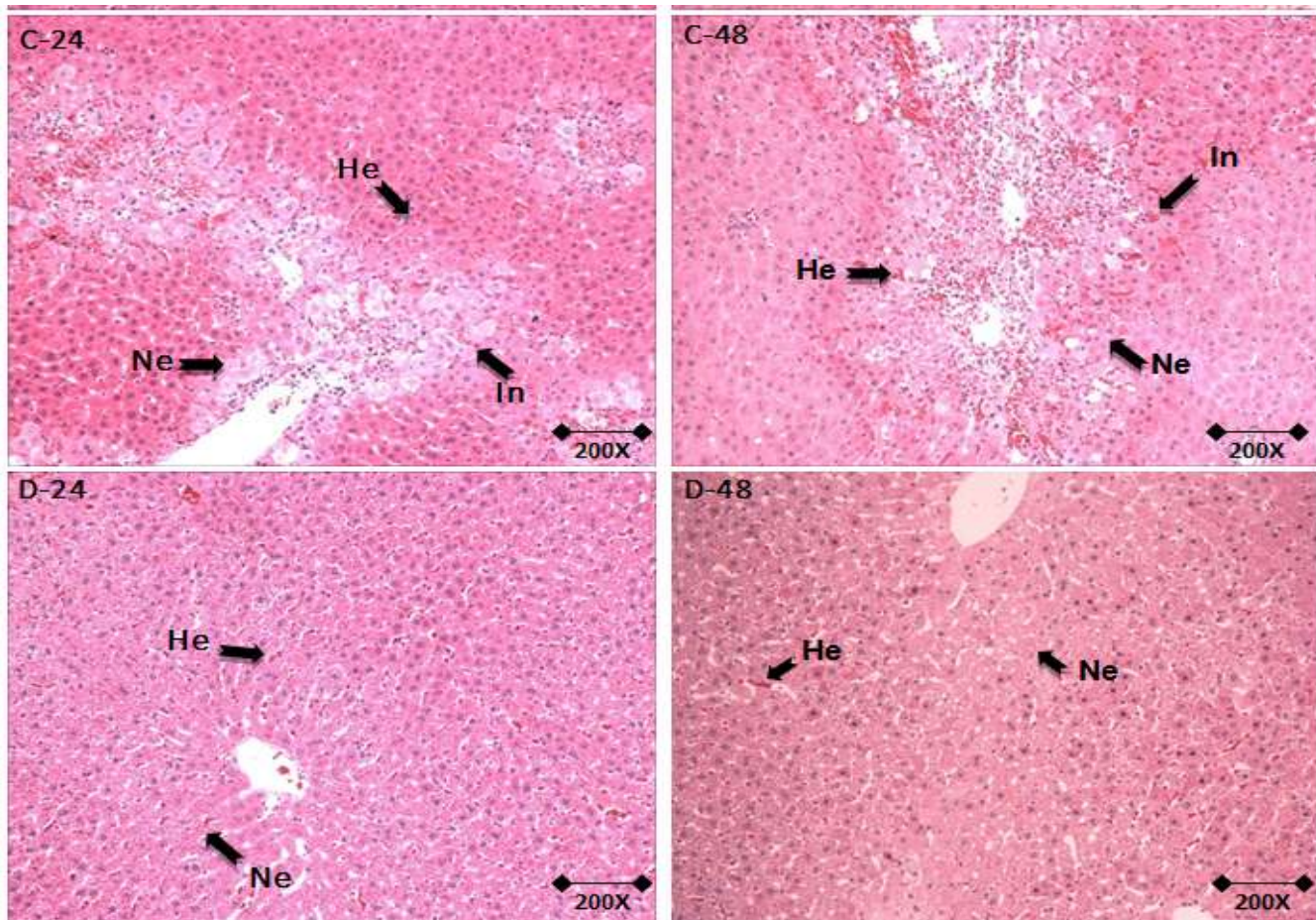

Figure 9. Photomicrograph of liver tissue in the $24 \mathrm{~h}$ (left column) and $48 \mathrm{~h}$ (right column) experiments. In A and $\mathrm{B}$ note the normality of the architecture in the hepatic parenchyma present in the CO and CO+MLT groups, respectively. C corresponds to the TAA group, black arrows indicate necrosis $(\mathrm{N})$, inflammatory infiltrate (In) and hemorrhage (He). In D note that for the TAA+MLT groups, there is evidence of parenchymal restructuring, with less damage and reduced manifestations of $\mathrm{He}$ and $\mathrm{Ne}$.
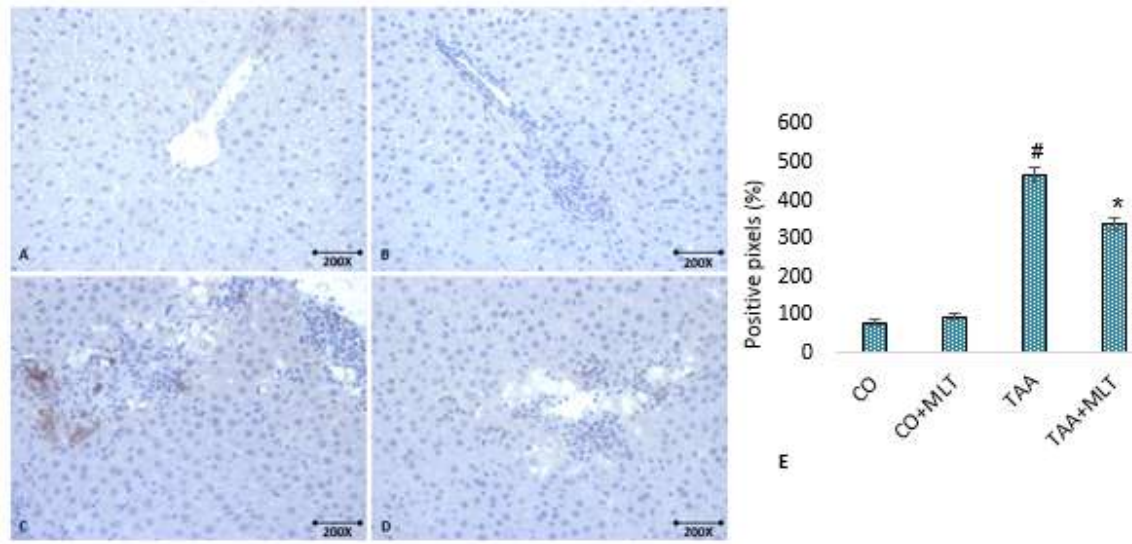

Figure 10. Immunohistochemical expression of nitric oxide synthethases (iNOS) in acute liver failure (ALF) model 24 hours after induction with thioacetamide (TAA) at 200x magnification. (A) CO group, (B) CO+MLT group, (C) TAA group, (D) TAA+MLT group, (E) quantification by $\%$ of positive pixels $(*, *$ p $<0.001) . \mathrm{n}=28$.

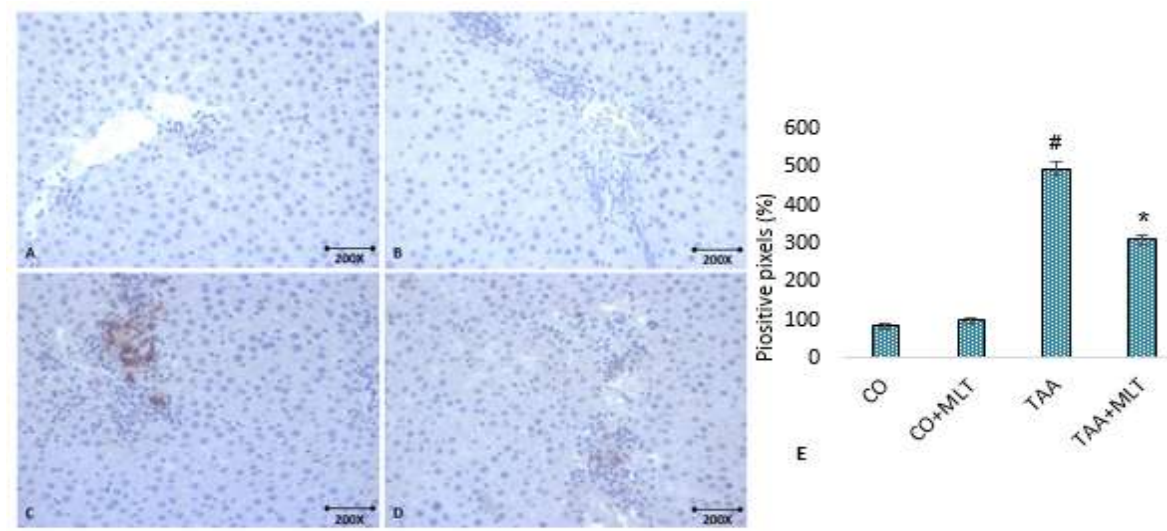


Figure 11. Immunohistochemical expression of nitric oxide synthethases (iNOS) in acute liver failure (ALF) model 48 hours after induction with thioacetamide (TAA) at 200x magnification. (A) CO group, (B) CO+MLT group, (C) TAA group, (D) TAA+MLT group, (E) quantification by $\%$ of positive pixels (*, $\mathrm{p}<0.001) . \mathrm{n}=28$.
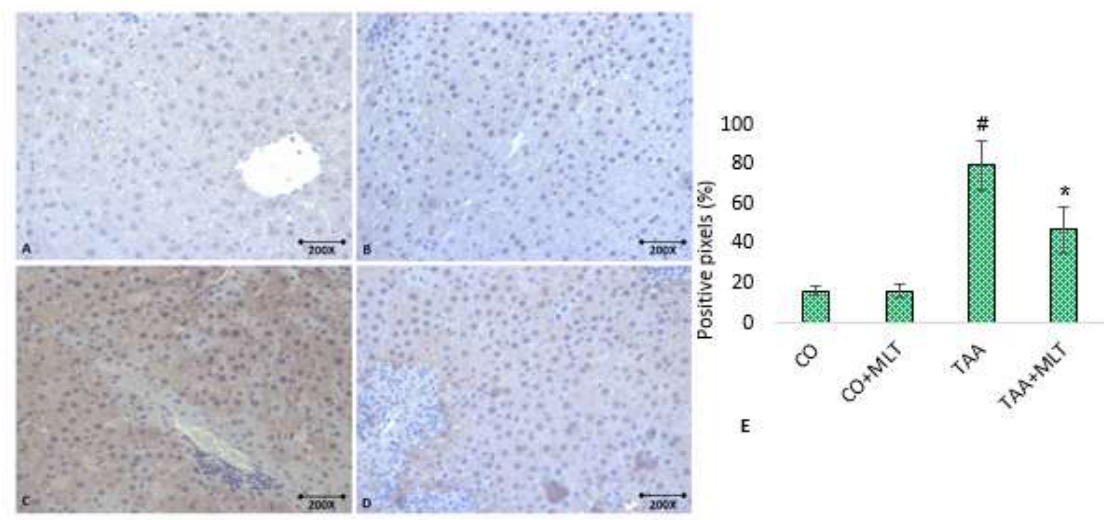

Figure 12. Immunohistochemical expression of nuclear kappa-B transcription factors (NF- $\mathrm{B})$ in acute liver failure (ALF) model 24 hours after induction with thioacetamide (TAA) at 200x magnification. (A) CO group, (B) CO+MLT group, (C) TAA group, (D) TAA+MLT group, (E) quantification by $\%$ of positive pixels (*, $\left.{ }^{\#} \mathrm{p}<0.001\right) . \mathrm{n}=28$.
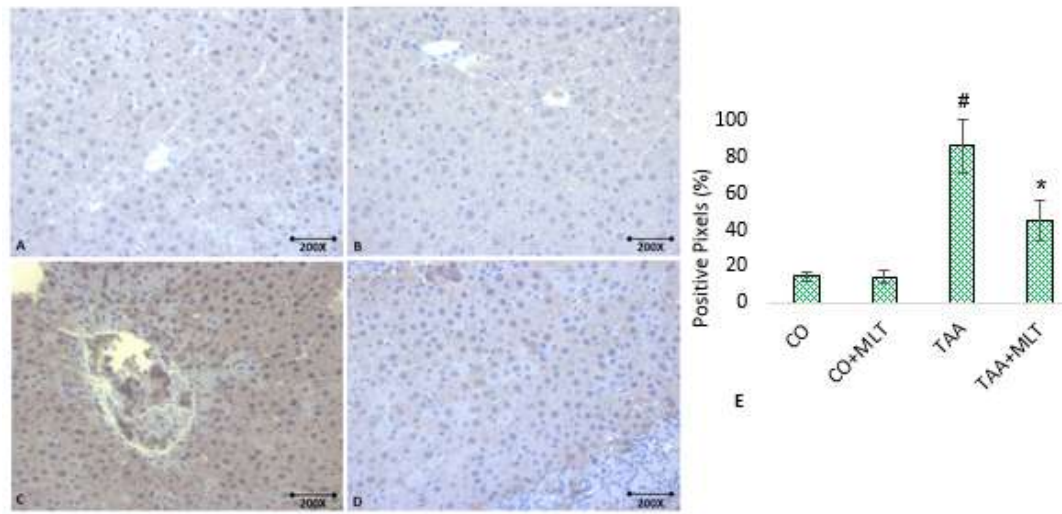

Figure 13. Immunohistochemical expression of nuclear kappa-B transcription factors $(\mathrm{NF}-\kappa \mathrm{B})$ in acute liver failure (ALF) model 48 hours after induction with thioacetamide (TAA) at 200x magnification. (A) CO group,

(B) CO+MLT group (C) TAA group, (D) TAA+MLT group, (E) quantification by \% of positive pixels (*, $\left.{ }^{\#} \mathrm{p}<0.001\right) . \mathrm{n}=28$.
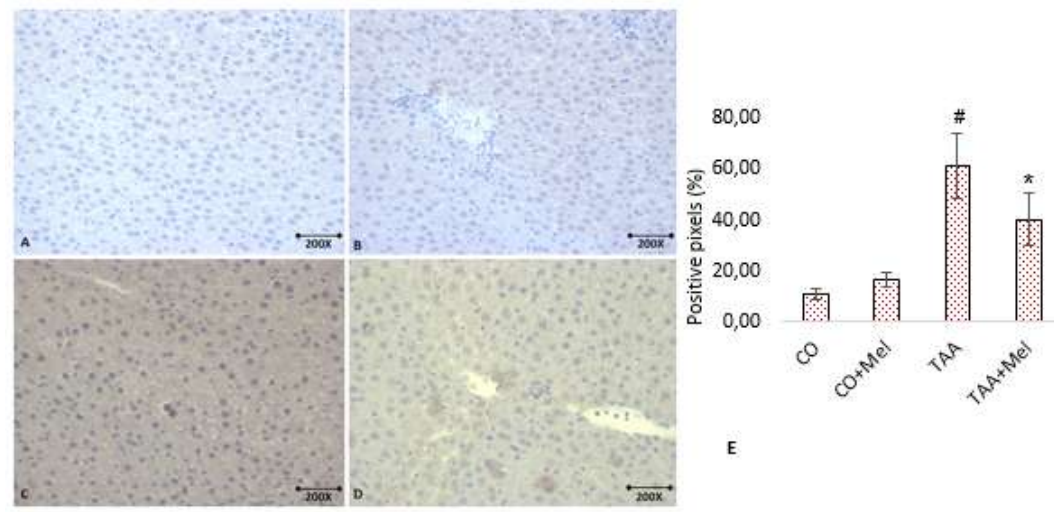

Figure 14. Immunohistochemical expression of tumor necrosis factor (TNF- $\alpha$ ) in acute liver failure (ALF) model 24 hours after induction with thioacetamide (TAA) at 200x magnification. (A) CO group, (B) CO+MLT group, (C) TAA group, (D) TAA+MLT group, (E) quantification by\% of positive pixels $(*, \#$ p $<0.001) . n=28$. 


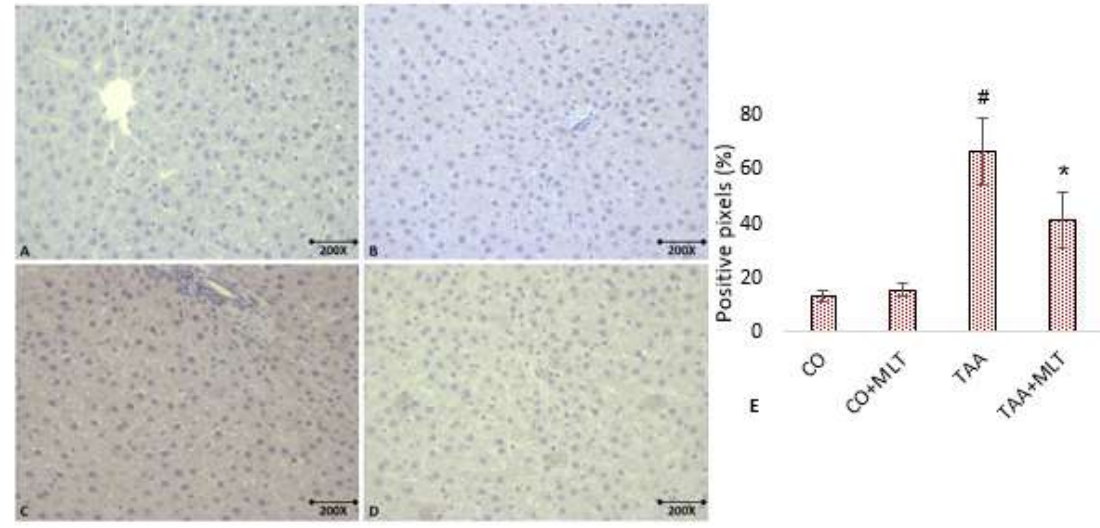

Figure 15. Immunohistochemical expression of tumor necrosis factor alpha (TNF- $\alpha$ ) in acute liver failure (ALF) model 48 hours after induction with thioacetamide (TAA) at 200x magnification. (A) CO group, (B) CO+MLT group, (C) TAA group, (D) TAA+MLT group, (E) quantification by $\%$ of positive pixels $(*$, $\mathrm{p}<0.001)$. $\mathrm{n}=28$.

The antioxidant effect of MLT may be attributed to its own molecular structure, because the indole nucleus is the primary point of interaction because it has high resonance stability and low activation energy barrier towards ROS. Despite the contribution of side chains, carbon 3 is the functional grouping capable of receiving the electrophilic addition, even though there are reports of variations of complexes formed with other sites of the molecule [66-67].

In addition, MLT has different metabolites that exhibit variations in functional groups and, thus, possess distinct biological properties and rates of electron consumption [68-69].

Synthetic compounds derived from MLT have been studied so that the analysis of structure-activity relationship enhance the understanding of receptors and the antioxidant mechanism in the different pathological conditions reported in the literature, including liver dysfunctions [70-71].

\section{Conclusion}

These results show that there is no difference between the studied times. Notably, survival was higher in the $24 \mathrm{~h}$ experiment, and liver damage was slightly greater in the $48 \mathrm{~h}$ experiment in the TAA groups. However, no difference was observed concerning the effects of MLT on the treated groups in either period.

MLT administration was able to restore serum levels of liver enzymes related to hepatic integrity, reduce lipid peroxidation, decrease SOD, GPX and GST activities, as well as increase CAT activity. Furthermore, there was a decrease in nitric oxide metabolites levels, restructuring of liver tissue integrity, and reduction of the immunohistochemical expression of inflammatory markers iNOS, NF- $\kappa$ B and TNF- $\alpha$.

Advances in studies with MLT in the TAA-induced ALF model, considering its interaction with different inflammatory markers related to cell death, as well as elucidation of the molecular mechanisms of action of MLT, can help to narrow the distance between bench and hospital bed, thus promoting the translational aspect.

\section{Acknowledgments}

The authors acknowledge the Graduate Program of Cell and Molecular Biology Applied to Health of the Lutheran University of Brazil, the Lutheran University Center of Ji-Parana, the Laboratory of Oxidative Stress and Antioxidants of the Lutheran University of Brazil, the Laboratory of Hepatology and Gastroenterology of the Hospital das Clinicas of Porto Alegre, the Federal University of Rio Grande do Sul, the Coordination for Higher Education Improvement (CAPES), and the National Council for Scientific and Technological Development (CNPq).

\section{References}

[1] Panackel C, Thomas R, Sebastian B, Mathai SK. Recent advances in management of acute liver failure. Indian J Critic Care. 2015;19(1): 27-33.

[2] Soultati A, Dourakis S. Pathogenesis of Fulminant Hepatic Failure. Ann Gastroenterol, North America. 2007;19(4): 313-24.

[3] Romero M, Palmer SL, Kahn JA, Ihde L, Lin LM, Kosco A, et al. Imaging appearance in acute liver failure: correlation with clinical and pathology findings. Dig Dis Sci. 2014;59(8): 1987-95.

[4] Lee WM, Sstravitz RT, Larson AM. Introduction to the revised American association for the study of liver diseases position paper on acute liver failure. Hepatology. 2012;55: 965-7.

[5] Bernal W, Wendon J. Acute Liver Failure. N Engl J Med. 2013; 369:2525-34.

[6] Bonomini F, Rodella LF, Rezzani R. Metabolic Syndrome, Aging and Involvement of Oxidative Stress. Aging Dis. 2015;6(2): 10920. 
[7] Roul D, Recchia FA. Metabolic Alterations Induce Oxidative Stress in Diabetic and Failing Hearts: Different pathways, same outcome. Antioxid Redox Signal. 2015.

[8] Vasallo C, Gastaminza P. Cellular stress responses in Hepatitis C virus infection: mastering a two-edged sword. Virus Res. 2015;pii:S01681702(15)00131-8.

[9] Miyanishi K, Hoki T, Tanaka S, Kato J. Prevention of hepatocellular carcinoma: Focusing on antioxidant therapy. World J Hepatol. 2015;7(3): 593-9.

[10] Portal-Núñez S, Esbrit P, Alcaraz MJ, Largo R. Oxidative stress, autophagy, epigenetic changes and regulation by miRNAs as potential therapeutic targets in osteoarthritis. Biochem Pharmacol. 2015.

[11] Zhou L, Zhao D, An H, Zhang H, Jiang C, Yang B. Melatonin prevents lung injury induced by hepatic ischemia-reperfusion through anti-inflammatory and anti-apoptosis effects. Int Immunopharmacol. 2015;29: 462-467.

[12] Galano, A, Castañeda-Arriaga R, Pérez-González A, Tan, D.-X, Reiter RJ. Phenolic Melatonin-Related Compounds: Their Role as Chemical Protectors against Oxidative Stress. Molecules. 2016: 21, 1442.

[13] Pi H, Xu S, Reiter RJ, Guo P, Zhang L, Li Y, et al. SIRT3-SOD2-mROS-dependent autophagy in cadmium-induced hepatotoxicity and salvage by melatonin. Autophagy. 2015.

[14] Korkmaz A, Reiter RJ, Topal T, Manchester LC, Oter S, Tan DX. Melatonin: An Established Antioxidant Worthy of Use in Clinical Trials. Mol Med. 2009;15(1-2): 43-50.

[15] Agil A, El-Hammadi M, Jiménez-Aranda A, Tassi M, Abdo W, Fernández-Vázquez G, Reiter RJ. Melatonin reduces hepatic mitochondrial dysfunction in diabetic obese rats. J Pineal Res. 2015;59(1): 70-9.

[16] Schemitt EG, Colares JR, Hartmann RM, Morgan-Martins MI, Marroni CA, Tuñón MJ, Marroni NP. Effect of glutamine on oxidative stress and inflammation in a rat model of fulminant hepatic failure. Nutr Hosp. 2016; 33(2): 210-19.

[17] Botelho F, Silva C, Cruz F. Epidemiologia explicada - análise de sobrevivência. Acta Urol. 2009;26(4): 33-38

[18] Brasil. Ministério da Ciência, Tecnologia e Inovação. Conselho Nacional de Controle de Experimentação Animal - CONCEA. Diretrizes da prática de eutanásia do CONCEA. Resolução normativa nº13; 2013.

[19] Bradford MM. A rapid and sensitive method for the quantitation of microgram quantities of protein utilizing the principle of protein-dye binding. Anal Biochem. 1976;72: 248-54

[20] Buege JA, Aust SD. Microsomal lipid peroxidation. Method Enzymol 1978;52: 302-10.

[21] Mirsa HP, Fridovich I. The role of superoxide anion in the autoxidation of epinephrine and a simple assay for superoxide dismutase. J Biol Chem 1972;247: 3170-5.

[22] Boveris A, Chance B. The mitochondrial generation of hydrogen peroxide. Biochem J. 1973;134: 707-16.

[23] Flohe L, Gunzler WA. Assays of glutathione peroxidase. Method Enzymol. 1984;105: 114-21.

[24] Mannervik B, Gluthenberg C. Glutationa Transferase. Method Enzymol. 1981;77: 731-5.

[25] Granger DL, Anstey NM, Miller WC, Weinberg JB. Measuring nitric oxide production in human clinical studies. Method Enzymol 1999;301:49-61.

[26] Maes M, Vinken M, Jaeschke H. Experimental models of hepatotoxicity related to acute liver failure. Toxic Appl Pharmacol. 2016;290:86-97.

[27] Koen YM, Sarma D, Hajovsky H, Galeva NA, Williams TD, Staudinger JL, Hanzlik RP. Protein Targets of Thioacetamide Metabolites in Rat Hepatocytes. Chem Res Toxicol. 2013;26(4): 564-74.

[28] Abdelaziz RR, Elkashef WF, Said E. Tranilast reduces serum IL-6 and IL-13 and protects against thioacetamide-induced acute liver injury and hepatic encephalopathy. Environ Toxicol and Phar. 2015;40: 259-267.

[29] Shirato T, Homma T, Lee J, Kurahashi T, Fujii J. Oxidative stress caused by a SOD1 deficiency ameliorates thioacetamide-triggered cell death via CYP2E1 inhibition but stimulates liver steatosis. Arch Toxicol. 2016:1-15.

[30] Zhang H, Liu D, Wang X, Chen X, Long Y, Chai W, Zhou X, Rui X, Zhang Q, Wang H, Yang Q. Melatonin improved rat cardiac mitochondria and survival rate in septic heart injury J. Pineal Res. 2013; 55:1-6

[31] Fink T, Glas M, Wolf A, Kleber A, Reus E, Wolf M, Kiefer D, Wolf B, Rensing H, Volk T, Matheus AM, Melatonin Receptors Mediate Improvements of Survival in a Model of Polymicrobial Sepsis. Crit Care Med. 2014;42(1): 22-31.

[32] O’Neal-Moffitt G, Delic V, Bradshaw PC, Olcese J. Prophylactic melatonin significantly reduces Alzheimer's neuropathology and associated cognitive de deficits independent of antioxidant pathways in A $\beta P P($ swe)/PS1 mice. Mol Neurodegener. 2015;11: 10-27.

[33] Laothong U, Pinlaor P, Boonsiri P, Pairojul C, Priprem A, Johns NP, Charoensuk L, Intuyod K, Pinlaor S. Melatonin inhibits cholangiocarcinoma and reduces liver injury in Opisthorchis viverrini-infected and N-nitrosodimethylamine-treated hamsters. J Pineal Res. 2013;55: 257-66.

[34] Sookoian S, Pirola CJ. Liver enzymes, metabolomics and genome-wide association studies: From systems biology to the personalized medicine. World J Gastroenterol 2015 January 21; 21(3): 711-25.

[35] Koeppen BM, Stanton BA [Org]. Berne \& Levy: Fisiologia, 6ed. Rio de Janeiro: Elsevier, 2009. 859 p.

[36] MacPhee SJ, Ganong WF. Fisiopatologia da doença: uma introdução à medicina clínica. Porto Alegre: AMGH, 2011.651p.

[37] Ozsoy M, Gonul Y, Ozkececi ZT, Bali A, Celep RB, Koçak A, Adali F, Tosun M, Celik S. The protective effect of melatonin on remote organ liver ischemia and reperfusion injury following aortic clamping. Ann Ital Chir. 2016;87: 271-9.

[38] Shokrzadeh M, Ahmadi A, Naghshvar F, Chabra A, Jafarinejhad M. Prophylactic efficacy of Melatonin on cyclophosphamideinduced Liver Toxicity in Mice. Biomed Res Int. 2014; 47045, 9p.

[39] De-David C, Silveira TR, Marroni NP. Modelos experimentais de insuficiência hepática fulminante (IHF). In: Marroni (Org). Estresse oxidativo e inflamação: dos modelos experimentais à clínica. Canoas: Ed. ULBRA, 2008, p. 144-45.

[40] Czechowska G, Celinski K, Korolczuk A, Wojcicka G, Dudka J, Bojarska A, Reiter RJ. Protective effects of melatonin against thioacetamide-induced liver fibrosis in rats. J physiol and pharmacol. 2015;66(4): 567-79.

[41] Colares J, Schemitt EG, Hartmann RM, Licks F, Soares MC, Bosco AD, Marroni NP Melatonin reduces endoplasmic reticulum stress and autophagy in liver of leptin-deficient mice. J Gastro. 2016; $22: 8918$.

[42] Esteban-Zubero E, Alatorre-Jiménez MA, López-Pingarrón L, Reyes-Gonzales MC, Souza PA, Cantín-Golet A, Ruiz-Ruiz FC, Xian Tan D, García-García JJ, Reiter RJ. Melatonin's role in preventing toxin-related and sepsis-mediated hepatic damage: a review. Pharmacol Res. 2016;105: 108-20.

[43] Li S, Tan H-Y, Wang N, et al. The Role of Oxidative Stress and Antioxidants in Liver Diseases. Piva T, ed. Int J Mol Sci. 2015;16(11): 26087-124.

[44] Rosa DP, Bona S, Simonetto D, Zettler C, Marroni CA, Marroni NP. Melatonin protects the liver and erythrocytes against oxidative stress in cirrhotic rats. Arq Gastroenterol. 2010;47(1)72-78.

[45] Taziki S, Sattari MR, Dastmalchi S, Eghbal MA. Cytoprotective Effects of Melatonin Against Amitriptyline-Induced Toxicity in Isolated Rat Hepatocytes. Adv Pharm Bull, 2015;5(3): 329-34. 
[46] Luxán-Delgado B, Potes Y, Rubio-Gonzáles A, Caballero B, Solano JJ, Fernández-Fernández M, Bermudéz M, Guimarães MRM, Veja-Naredo I, Boga JÁ, Coto-Montes A. Melatonin reduces endoplasmic reticulum stress and autophagy in liver of leptin-deficient mice. J. Pineal Res. 2016;61(1): 108-23.

[47] Shimizu T, Nojiri H, Kawakami S, Uchiyama S, Shirasawa T. Model mice for tissue-specific deletion of the manganese superoxide dismutase gene Geriatr Gerontol Int 2010;10(Suppl. 1): S70-79.

[48] Demirtas CY, Pasaoglu OT, Bircan FS, Kantari S, Turkozkan N. The investigation of melatonin effect on liver antioxidant and oxidant levels in fructose-mediated metabolic syndrome model. Eur Rev Med Pharmacol Sci. 2015;19: 1915-21.

[49] Madhu P, Reddy KP, Reddy PS. Melatonin Reduces Oxidative Stress and Restores Mitochondrial Function in the Liver of Rats Exposed to Chemotherapeutics. J. Exp. Zool. 2015;323A:301-08.

[50] Sokolovic D, Djordjevic B, Kocic G, Stoimenov TJ, Stanojkovic Z, Sokolovic DM, Veljkovic A, Ristic G, Despotovic M, Milisavljevic D, Jankovic R, Binic I. The Effects of Melatonin on Oxidative Stress Parameters and DNA Fragmentation in Testicular Tissue of Rats Exposed to Microwave Radiation. Adv Clin Exp Med 2015; 24(3): 429-36.

[51] Emamgholipour S, Hossein-nezhad A, Sahraian MA, Askarisadr F, Ansari M. Evidence for possible role of melatonin in reducing oxidative stress in multiples clerosis through its effect on SIRT1 and antioxidant enzymes. Life Sci. 2016;(145): 34-41

[52] Karaer IC, Simsek G, Yildiz A, Vardi N, Polat A, Tanbek K, Gurocak S, Parlakpinar H. Melatonin's protective effect on the salivary gland against ionized radiation damage in rats. J Oral Pathol Med. 2016;45(6):444-9

[53] Halliwell B. Free Radicals and Other Reactive Species in Disease. 2015. eLS.1-9.

[54] Verma D, Hashim OH, Jayapalan JJ, Subramanian P. Effect of melatonin on antioxidant status and circadian activity rhythm during hepatocarcinogenesis in mice J Cancer Res Therap. 2014;(10)4: 1040-44.

[55] Popov SS, Shulgin KK, Popova TN, Pashkov AN, Agarkov AA, Carvalho MAAP. Effects of Melatonin-Aided Therapy on the Glutathione Antioxidant System Activity and Liver Protection. J Biochem Mol Toxicol. 2015;29(10): 449-57.

[56] Marroni NP, Bona S, Rodrigues G, Moreira AJ, Silveira TR, Marroni CA. Melatonin protects the liver in an experimental model of cirrhosis. P0090. J Hepatol. 2015; 62: S263-S864.

[57] Janjetovic Z, Zachary PN, Hanna S, Jarrett SG, Kim TK, Reiter RJ, Slominski AT. Melatonin and its metabolites ameliorate UVBinduced damages in human epidermal keratinocytes. J Pineal Res. 2014;57(1): 90-102.

[58] Vinod C, Jagota A. Daily NO rhythms in peripheral clocks in aging male Wistar rats: protective effects of exogenous melatonin. Biogerontology. 2016; 1-13.

[59] Serikov VS, Lyashev YD. Effects of Melatonin on Stress-Induced Changes in the Liver of Rats with Different Resistance to Stress. Bull Exp Biol Med. 2015;159(3):314-17.

[60] Zhou H, Jiang C, Gu L, Liu YE, Xu Q. Influence of melatonin on IL-1Ra gene and IL-1 expression in rats with liver ischemia reperfusion injury. Biomed Rep. 2016;4(6): 667-72.

[61] Kireev R, Bitoun S, Cuesta S, Tejerina A, Ibarrola C, Moreno E, Vara E, Tresguerres JAF. Melatonin treatment protects liver of Zucker rats after ischemia/reperfusion by diminishing oxidative stress and apoptosis. Eur J Pharmacol. 2013;701: 185-93.

[62] Know YJ, Lee KG, Choi D. Clinical implications of advances in liver regeneration. Clin Mol Hepatol. 2015;21(1): 7-13.

[63] Ozsoy M, Gonul Y, Ozkececi ZT, Bali A, Celep RB, Koçak A, Adali F, Tosun M, Celik S. The protective effect of melatonin on remote organ liver ischemia and reperfusion injury following aortic clamping. Ann Ital Chir. 2016;87: 271-9.

[64] Cichoż-Lach H, Michalak A. Oxidative stress as a crucial factor in liver diseases. World J Gastroenterol. 2014;20(25): 8082-91.

[65] San-Miguel B, Crespo I, Vallejo D, Álvarez M, Prieto J, González-Gallego J, Tuñón MJ. Melatonin modulates the autophagic response in acute liver failure Induced by the rabbit hemorrhagic disease virus. J Pineal Res.2014;56: 313-21,

[66] Tan Dun-xian, Reiter RJ, Manchester IC, Yan Mei-ting, El-sawi M, Sainz RM et al. Chemical and Physical Properties and Potential Mechanisms: Melatonin as a Broad Spectrum Antioxidant and Free Radical Scavenger. Curr Top Med Chem. 2002;2: 181-97.

[67] Rosen J, Than NN, Koch D, Poeggeler B, Laatsch H, Hardeland R. nteractions of melatonin and its metabolites with the ABTS cation radical: extension of the radical scavenger cascade and formation of a novel class of oxidation products, $\mathrm{C} 2$-substituted 3indolinones. J Pineal Res. 2006;41(4):374-81

[68] Tan Dun-xian Hardeland R, Manchester LC, Galano A, Reiter RJ. Cyclic-3 hydroxymelatonin (C3HOM), a potent antioxidant, scavenges free radicals and suppresses oxidativereactions. Curr Med Chem. 2014;21(13):1557-65.

[69] Kneidinger H, Mitulovic G, Hartmann J, Quint RM, Getoff N. Melatonin: Free Radicals and Metabolites Resulting by Emission and Consumption of Solvated Electrons (eaq-): Reaction Mechanisms. In Vivo. 2015;29(5): 605-9.

[70] Buendia I, Navarro E, Michalska P, Gameiro I, Egea J, Abril S et al. New melatonin-cinnamate hybrids as multi-target drugs for neurodegenerative diseases: Nrf2-induction, antioxidant effect and neuroprotection. Future Med Chem. 2015;7(15):1961-9.

[71] Emet M, Ozcan H, Ozel L, Yayla M, Halici Z, Hacimuftuoglu A. A Review of Melatonin, Its Receptors and Drugs. Eurasian J Med. 2016;48(2):135-41. 